Results We have 4 patients in pediatric population where radial approach was used. Indications included Juvenile Nasopharyngeal Angiofibroma embolization (2), right ICA pseudoaneurysm which failed medical management (1), and right cerebellar AVM (1). In all cases, a $6 \mathrm{~F}$ sheath with a $6 \mathrm{~F}$ ENVOY guide catheter (Codman- DePuy Synthes, Raynam, MA) were used. One patient developed radial artery vasospasm, and $5 \mathrm{mg}$ verapamil were administered intraarterially post procedure before removal of sheath. The patient did not have any complaints post-procedurally. All preprocedural objectives were met, and none of the interventions required changing to a transfemoral approach. The radial artery remained patent in all 4 patients post-procedurally.

Conclusion TRA is safe, effective, and well tolerated in appropriately selected pediatric population. Most importantly, the risk of bleeding and arterial damage, the most common complications following these procedures, is essentially eliminated with the Transradial approach. Ultrasound guided measurement of the artery to ensure caliber over $2 \mathrm{~mm}$ is recommended in this population to avoid complications.

Disclosures N. Majmundar: None. P. Patel: None. V. Dodson: None. I. Bach: None. J. Liu: None. P. Khandelwal: None.

\section{E-003 FIRST CASE OF FLOW DIVERTING STENT PLACEMENT IN A PEDIATRIC PATIENT THROUGH RADIAL ARTERY APPROACH}

${ }^{1}$ I Bach, ${ }^{2} \mathrm{P}$ Patel ${ }^{*},{ }^{2} \mathrm{~N}$ Majmundar, ${ }^{2} \mathrm{P}$ Khandelwal. ${ }^{1}$ Neurology, Rutgers University, Newark, NJ; ${ }^{2}$ Neurosurgery, Rutgers University, Newark, NJ

\subsection{6/neurintsurg-2019-SNIS.78}

Introduction While trans-radial access (TRA) has been previously described for coronary angiography in the pediatric population, TRA has not been well described in pediatric Neurointervention cases.

Case We present a case of flow diversion stent placement via the TRA in a 15-year-old female. The patient was found to have a traumatic right internal carotid artery dissection without any obvious pseudoaneurysm demonstrated on CTA and diagnostic angiography. She was started on anticoagulation. Three month follow-up MRA, demonstrated a new pseudoaneurysm measuring $8 \mathrm{~mm} \times 6 \mathrm{~mm}$ with a neck of $4 \mathrm{~mm}$. After discussion, we believed flow-diverting stent was optimal treatment in this patient. Her radial artery diameter was 2.1 $\mathrm{mm}$. Ultrasound guided micropuncture of the radial artery was performed using single wall technique followed by placement of a 6-French sheath the right radial artery. $6 \mathrm{~F}$ Envoy guide catheter was placed in the R ICA. The flow diverting stent was successfully placed without any adverse outcomes.

Conclusion Here we present feasibility of Pediatric flow diverting stent placement thought radial approach. Many Neurointerventionalists prefer transfemoral access due to familiarity as well as size of the vessel which allows for the use of larger systems. Furthermore, the TRA is often complicated by vasospasm as well as difficulty in catheterizing the contralateral ICA and VA. While there are minimal complications, the TRA carries benefits of increased comfort, faster recovery following intervention, and a significant decrease in morbidity and mortality from femoral access. As experience grows and the technique becomes more refined, we believe that TRA will become more ubiquitous for cerebrovascular intervention in the pediatric as well as adult populations.

Disclosures I. Bach: None. P. Patel: None. N. Majmundar: None. P. Khandelwal: None.

\section{E-004 THE UTILITY OF MICRO VASCULAR PLUG IN THE TREATMENT EMBOLIZATION OF VEIN OF GALEN MALFORMATION: A CASE REPORT, TECHNICAL CONSIDERATION, AND LITERATURE REVIEW}

M Mathkour*, E McCormack, J Berry, A Dumont, E Valle-Giler. Neurosurgery, Tulane Medical Center/Ochsner Medical Center, NEW ORLEANS, LA

\subsection{6/neurintsurg-2019-SNIS.79}

Background Vein of Galen malformations (VOGM) are rare, accounting in recent literature for approximately thirty percent of pediatric venous malformations, caused by abnormal venogensis during gestation. VOGM is divided into two categories,

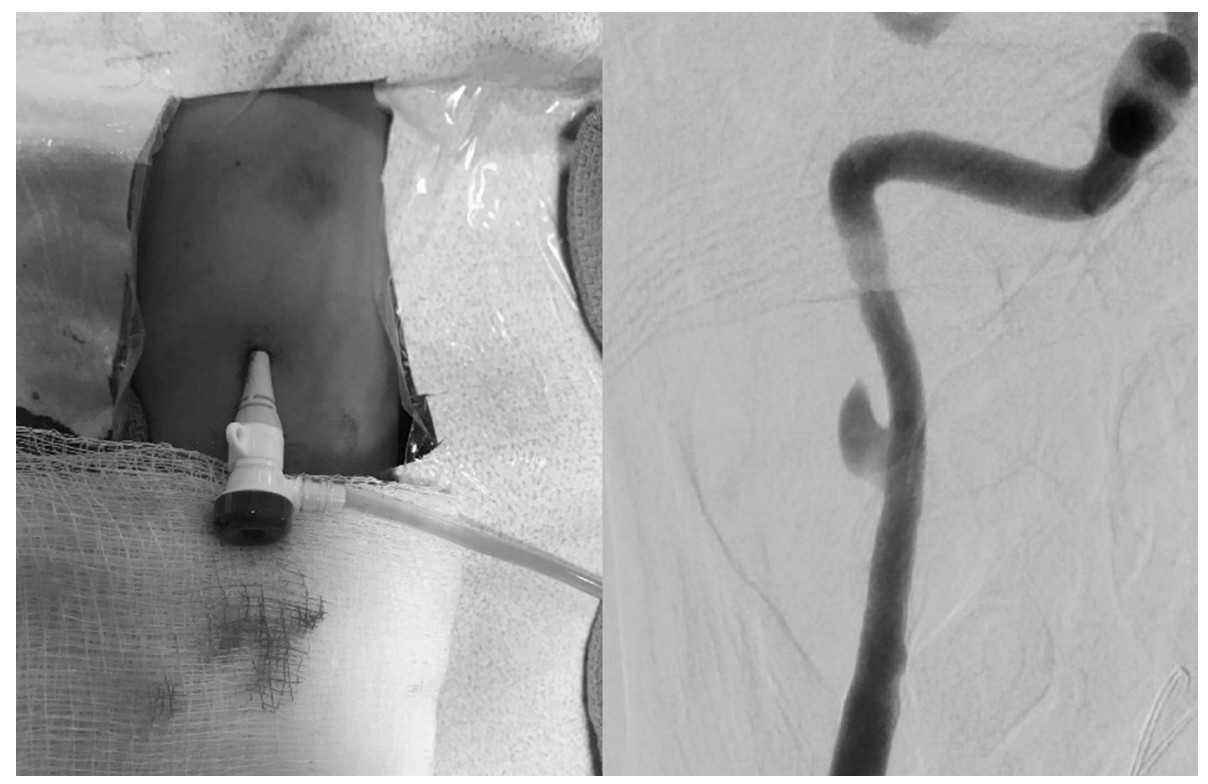

